\title{
Structure and Role of a Soluble Cytoplasmic Glucan from Phytophthora cinnamomi
}

\author{
By L. P. T. M. ZEVENHUIZEN* AND S. BARTNICKI-GARCIA \\ Department of Plant Pathology, University of California, \\ Riverside, California 92502, U.S.A.
}

(Accepted for publication I January 1970)

\begin{abstract}
SUMMARY
A soluble glucan was isolated from the mycelium of Phytophthora cinnamomi and found to be a $\beta$-I $\rightarrow 3$-linked glucan with branches arising from residues substituted at both C-3 and C-6. This glucan is an important reserve material of the fungus; it accumulates in mycelium grown in glucose-rich medium and disappears upon incubation in media devoid of glucose.
\end{abstract}

\section{INTRODUCTION}

$\beta$-Glucans seem to be the principal polysaccharides elaborated by the fungus Phytophthora cinnamomi. Two different $\beta$-glucans comprise nearly $90 \%$ of the mycelial walls of this oomycete (Bartnicki-Garcia, I966): cellulose is the minor component while the major wall constituent is a very insoluble branched glucan, linked predominantly by $\beta-\mathrm{I} \rightarrow 3$ bonds and $\beta$-I $\rightarrow 6$ links at the branching residues (Zevenhuizen \& Bartnicki-Garcia, 1969). As described below, an important reserve carbohydrate found in the mycelium of $P$. cinnamomi is also a $\beta-\mathrm{I} \rightarrow 3$ and $\beta$-I $\rightarrow 6$-linked glucan. Branched $\beta$-I $\rightarrow 3$-glucans with the branching residues substituted at both $\mathrm{C}-3$ and $\mathrm{C}-6$ are commonly found in fungi (see reviews: Clarke \& Stone, 1963; Gorin \& Spencer, 1968). The fine structure, physical properties, cellular location and probable function of these $\beta$-I $\rightarrow 3-\beta$-I $\rightarrow 6$-glucans vary: (I) Some are found dissolved in the culture medium (Bouveng, Kiessling, Lindberg \& McKay, 1963; Wallen, Rhodes \& Shulke, 1965; Buck, Chen, Dickerson \& Chain, 1968) and their function has yet to be defined. (2) Others are highly insoluble constituents of the cell wall fabric (see Bartnicki-Garcia, I968), where they probably play a key structural role. (3) Some occur in the cytoplasm and probably serve as $\mathrm{C}$ and energy reserves, e.g. the glucan from the sclerotia of Sclerotinia libertiana (Kitahara \& Takeuchi, 1959) and the one from P. cinnamomi, whose isolation and properties are described in the present paper.

\section{METHODS}

Cultivation. Phytophthora cinnamomi strain SB-2I6-I was studied. Mycelia were grown in $350 \mathrm{ml}$. prescription bottles containing $50 \mathrm{ml}$. of an asparagine+glucose medium previously described (Bartnicki-Garcia, 1966). The bottles were inoculated with Io ml. of a homogenized mycelial suspension derived from a liquid culture, and incubated horizontally in a BOD incubator at $25^{\circ}$. At harvest time, the cultures were

* On leave of absence from the Laboratory of Microbiology, Agricultural University, Wageningen, The Netherlands. 
filtered on a coarse sintered-glass filter and the mycelial mat washed with distilled water several times.

Glucan isolation. Mycelium grown for 7 days was washed and broken in a Bronwill MSK cell homogenizer as described earlier (Zevenhuizen \& Bartnicki-Garcia, 1969). The cell walls were centrifuged down, washed with water and weighed. The supernatant liquid was deproteinized by addition of trichloroacetic acid to $2.5 \%(\mathrm{w} / \mathrm{v})$. To the deproteinized solution, two volumes of $95 \%(\mathrm{v} / \mathrm{v})$ ethanol in water were added to precipitate the glucan. The resulting white precipitate was centrifuged down and dissolved in water; a small amount of insoluble residue was discarded. The glucan was again precipitated with 2 vol. of ethanol; a small amount of sodium acetate was added to facilitate precipitation. The glucan was washed successively with ethanol, and ethyl ether, and dried in air.

Chemical methods. Methylation analysis and periodate oxidation were done as before (Zevenhuizen \& Bartnicki-Garcia, 1969). Determinations of methoxyl and total- $\mathrm{N}$ were performed by the Schwarzkopf Microanalytical Laboratory, Woodside 77 , N.Y., U.S.A. Total hexose was determined by the anthrone reagent with glucose as a standard. The distribution of carbohydrate in mycelial fractions was also measured by the anthrone method. The fractions were obtained by extracting consecutively the washed mycelium harvested from each bottle with: (I) $20 \mathrm{ml} .70 \%$ (v/v) ethanol in water in a boiling water bath for $30 \mathrm{~min}$. (2) $20 \mathrm{ml}$. distilled water at $97^{\circ}$ for $30 \mathrm{~min}$. (3) $20 \mathrm{ml}$. I N-KOH at room temperature for $30 \mathrm{~min}$. The final residue was washed with water.

Enzymic methods. The action of $\alpha$-amylase was tested under conditions specified earlier (Zevenhuizen, 1966). Digestion with $\beta$-glucanases was tested with a crude mixture of $\beta$-I $\rightarrow 3$ and $\beta-\mathrm{I} \rightarrow 4$ endoglucanases from Streptomyces sp. QMB $8 \mathrm{I} 4$ (a gift from E. T. Reese, U.S. Army Laboratories, Natick, Mass., U.S.A.) under conditions as used before (Bartnicki-Garcia \& Lippman, 1967). After de-ionization on a mixed-bed column of Dowex-I-acetate and Dowex-50-hydrogen, the sugars were separated by descending paper chromatography with $n$-butanol + pyridine + water $(6+4+3$, by vol.) as solvent.

\section{RESULTS}

Properties of the cytoplasmic glucan. The glucan isolated from the cytoplasm of Phytophthora cinnamomi (see Methods) was a white powder soluble in water and also in hot $70 \%(\mathrm{v} / \mathrm{v})$ ethanol in water. It contained $96 \%$ anhydroglucose residues as measured by the anthrone method. A I $75 \%$ total-N value suggested a protein content of about $10 \%$. Whether this protein was merely a contaminant or an integral part of a glycoprotein complex was not investigated. The glucan did not give the characteristic colours of glycogen or starch when treated with iodine and was not attacked by $\alpha$-amylase. Its low specific optical rotation $[\alpha]_{D}^{25}-\mathrm{I} \cdot 2$ (about $5 \cdot 0$ in water) indicated a $\beta$-glucan. After digestion with a crude glucanase mixture from Streptomyces, a series of oligosaccharides was separated on paper chromatograms and corresponded in mobility to laminarin oligosaccharides; from glucose to the hexamer, a linear relationship was obtained between oligomer size and the $\log \mathrm{I}-\boldsymbol{R}_{F} / R_{F}$ (French $\&$ Wild, I953). There was also an unresolved streak of higher oligosaccharides extending to the origin. Cellobiose was not detected.

Structural analysis of the glucan. The cytoplasmic glucan was dissolved in dimethyl 
sulphoxide and methylated by the Hakomori (1964) procedure as described by Sandford \& Conrad (1966). After methylation, the glucan showed a $-\mathrm{OCH}_{3}$ content of $42 \cdot 75 \%$ and $\mathrm{N}$ content of $0.00 \%$. The methylated glucan was hydrolysed with $72 \%(\mathrm{w} / \mathrm{v})$ $\mathrm{H}_{2} \mathrm{SO}_{4}$ at room temperature for $\mathrm{I} \mathrm{hr}$. The acid was diluted to $8 \%$ with water and the hydrolysis completed at $100^{\circ}$ for $18 \mathrm{hr}$. The resulting mixture of glucose-O-methyl ethers was separated by gas-liquid partition chromatography (GLC) after conversion to the corresponding methyl glucosides. Three different anomeric pairs of O-methyl ethers were recognized (Table I). Similarly, three different fractions of glucose-Omethyl ethers were separated by cellulose column chromatography corresponding to those resolved by GLC. From $400 \mathrm{mg}$. of hydrolysate applied to the cellulose column, the following fractions were obtained and characterized: (a) 2,3,4,6-tetra-O-methyl-Dglucose, $42 \mathrm{mg}$.; on crystallization from light petroleum (b.p. 30 to $70^{\circ}$ ) gave a product with m.p. $76^{\circ}$ to $85^{\circ}$; (b) 2,4,6-tri-O-methyl-D-glucose, $258 \mathrm{mg}$.; on recrystallization from ethyl ether showed m.p. and mixed m.p. $123^{\circ}$ to $125^{\circ}$ and $[\alpha]_{D}^{25}+\operatorname{IOS}(\mathrm{I}$ min.) $\rightarrow$ +75 (24 hr) (about 0.I in water); (c) 2,4-di-O-methyl-D-glucose, $49 \mathrm{mg}$.; this compound could not be crystallized as such; upon conversion into $N$-p-nitrophenyl-2,4di-O-methyl-D-glucosylamine it afforded crystals from an ethyl acetate solution with m.p. and mixed m.p. $242^{\circ}$ to $245^{\circ}$.

\section{Table I. Methylation analysis of the soluble cytoplasmic glucan of Phytophthora cinnamomi}

Methylated derivatives prepared and analysed by gas-liquid chromatography, as previously described (Zevenhuizen \& Bartnicki-Garcia, 1969).

$\begin{array}{lc}\text { Methyl-D-glucoside ethers } & \text { Mole (\%) } \\ \text { 2,3,4,6-tetra-O-methyl ether } & \text { II } \cdot 3 \\ \text { 2,4,6-tri-O-methyl ether } & 76 \cdot 7 \\ \text { 2,4-di-O-methyl ether } & 12 \cdot 2\end{array}$

The total values of periodate consumed and formic acid released, after oxidation of the glucan with periodate, were calculated by extrapolation to zero time to correct for over-oxidation (Fig. I). The glucan consumed 0.3 moles periodate and yielded

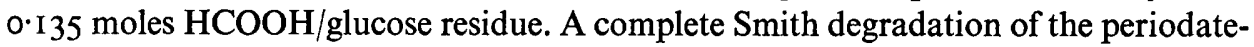
oxidized glucan was done. The glucan was oxidized with periodate for 3 days at room temperature, then reduced with sodium borohydride and hydrolysed with $2 \mathrm{~N}-\mathrm{H}_{2} \mathrm{SO}_{4}$ for $16 \mathrm{hr}$ at $100^{\circ}$. After acetylation, two degradation products were separated by GLC, namely glycerol triacetate and glucose penta-acetate, in amounts corresponding, respectively, to 0.226 moles and $0.774 \mathrm{moles} / \mathrm{mole}$ glucose residue. Erythritol tetraacetate was not detected.

Accumulation and utilization of cytoplasmic glucan. The amount of cytoplasmic glucan isolated from the mycelium of Phytophthora cinnamomi was very dependent on the glucose concentration in the culture medium (Table 2). The utilization of stored carbohydrate was shown in the following experiment. Two sets of five bottles of asparagine + glucose medium were inoculated with a suspension of mycelium homogenized in a Sorvall Omni-Mixer; after 4 days incubation one set of cultures was harvested for analysis. The liquid medium of the other set of cultures was replaced with glucose-free asparagine medium, and the incubation continued for 4 more days. The change of culture medium was accomplished in situ by using a sintered-glass 
immersion filter and a water aspirator. All manipulations were done aseptically. After removing the spent culture medium the mycelium was washed three times with asparagine medium (glucose omitted), resuspended in $50 \mathrm{ml}$. of glucose-free asparagine medium and the incubation resumed for 4 more days. The mycelium from each bottle

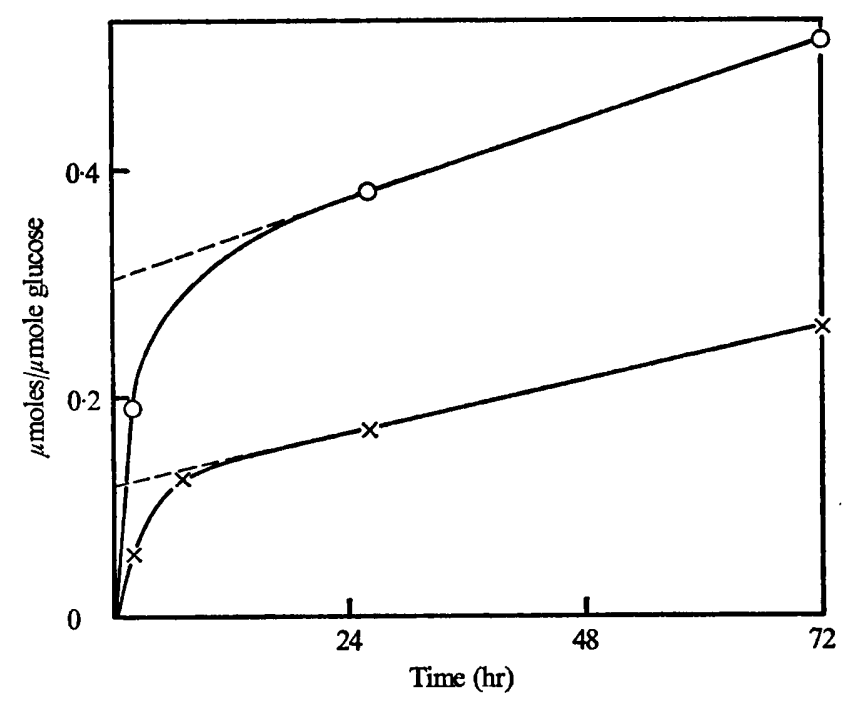

Fig. I. Periodate oxidation of the cytoplasmic glucan of Phytophthora cinnamomi. $\mathrm{O}-\mathrm{O}$,

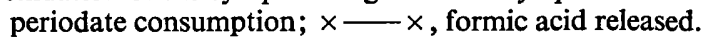

Table 2. Effect of two glucose concentrations on glucan formation by Phytophthora cinnamomi

Values correspond to $500 \mathrm{ml}$. asparagine + glucose culture incubated for 7 days.

$\begin{array}{cccc}\begin{array}{c}\text { Initial glucose } \\ \text { conc. }\end{array} & \begin{array}{c}\text { Cell yield } \\ (\text { g. wet wt) }\end{array} & \begin{array}{c}\text { Cell walls } \\ \text { (g. dry wt) }\end{array} & \begin{array}{c}\text { Cytoplasmic glucan } \\ \text { (g. dry wt) }\end{array} \\ \mathbf{2 . 0} \% & 2 \mathrm{I} \cdot 3 & \mathbf{I} .43 & 0.36 \\ 0.5 \% & 13.9 & 0.90 & 0.024\end{array}$

Table 3. Changes in carbohydrate content following glucose deprivation of the mycelium of Phytophthora cinnamomi

\begin{tabular}{|c|c|c|}
\hline & \multicolumn{2}{|c|}{ Carbohydrate content* } \\
\hline Fraction & $\begin{array}{c}\text { Before } \\
\text { deprivation } \dagger \\
\text { (mg. } / 50 \mathrm{ml} \text {. culture) }\end{array}$ & $\begin{array}{r}\text { After } \\
\text { deprivatio } \\
\text { (mg./50 ml. cu }\end{array}$ \\
\hline $10 \%(\mathrm{v} / \mathrm{v})$ ethanol in water-soluble & $35 \cdot I$ & II $\cdot 7$ \\
\hline vater-soluble & $1 \cdot 3$ & $I \cdot 2$ \\
\hline H-soluble & 0.4 & $0 \cdot 3$ \\
\hline uble residue & $14 \cdot 8$ & $20 \cdot 1$ \\
\hline Total & $51 \cdot 6$ & $33 \cdot 3$ \\
\hline
\end{tabular}

* Determined by anthrone method and expressed as $\mathrm{mg}$. glucose/culture (50 $\mathrm{ml}$.).

$\uparrow$ Grown for 4 days in asparagine + glucose medium.

$\ddagger$ Grown for 4 days in asparagine + glucose medium followed by 4 days in glucose-free asparagine medium. 
was harvested, washed with water by centrifugation and extracted consecutively (see Methods). Table 3 shows the changes in carbohydrate content in the mycelial fractions caused by glucose deprivation. Glucose deprivation effected a substantial decrease in the total amount of carbohydrate in the mycelium and a marked redistribution of these carbohydrates. The most conspicuous changes were the large decrease in soluble carbohydrate (hot $70 \%(\mathrm{v} / \mathrm{v})$ ethanol in water soluble fraction), and the increase in cell-wall glucan (insoluble residue). The decrease in ethanol-soluble carbohydrate shows extensive consumption of cytoplasmic glucan which comprises $77 \%$ of the carbohydrate in this fraction. In another experiment glucose deprivation was prolonged for 19 days by which time the $70 \%(\mathrm{v} / \mathrm{v})$ ethanol in water soluble carbohydrates had been nearly all consumed; only I $\%$ of the initial value remained.

\section{DISCUSSION}

The methylation analysis indicated that the cytoplasmic glucan of Phytophthora cinnamomi is built predominantly $(76 \cdot 7 \%$ ) of glucose residues substituted at $\mathrm{C}-3$, with branchings at some residues (12.2\%) substituted at both $\mathrm{C}-3$ and C-6; the remaining glucose units $(\mathrm{II} \cdot \mathrm{I} \%)$ are non-reducing terminal groups. Theoretically, such glucan would consume 0.22 moles periodate, and yield 0.1 I moles formic acid per mole of glucose residue; however, the experimental values were higher. The discrepancy probably resulted, despite the extrapolation correction, from underestimation of the large extent of over-oxidation. Also, over-oxidation probably accounted for the amount of Smith degradation products observed. Thus only $77 \%$ of the initial glucose residues survived periodate oxidation, against the $89 \%$ of periodate-resistant residues predicted from the methylation data; instead a corresponding large proportion of glycerol was obtained. There was, however, no erythritol indicative of $I \rightarrow 4$-linked glucose residues, in agreement with the methylation data. The evidence from the methylation analysis, periodate oxidation, $\beta$-glucanase digestion and optical rotation support the view that the cytoplasmic glucan of $P$. cinnamomi is a branched $\beta-\mathrm{I} \rightarrow 3^{-}$ linked glucan with $\mathrm{I} \rightarrow 6$ links at the branching residues. The methylation data also indicate that there are, on the average, eight glucose residues per branching point. The relative orientation of the $I \rightarrow 3$ and $I \rightarrow 6$ linkages on the branching glucose units and the length of, and spacing between, branches remains to be determined. The soluble cytoplasmic glucan of $P$. cinnamomi resembles in part the very insoluble glucan found in the cell walls of this fungus; both have mainly $\beta-I \rightarrow 3$ links, and $I \rightarrow 6$ links at the branching points, but differ in the degree of branching and, seemingly, in the presence of $\mathrm{I} \rightarrow 4$ links which appear to be associated with the wall glucan only (Zevenhuizen \& Bartnicki-Garcia, 1969).

Some Phytophthora species (Eschrich, 1956) and other related genera of Oomycetes (Mangin, I894) have long been known to give positive staining tests for callose. The $\beta-\mathrm{I} \rightarrow 3-\beta-\mathrm{I} \rightarrow 6$ glucans found previously in the cell walls and now in the cytoplasm of $P$. cinnamomi are possible candidates responsible for this staining reaction, characteristic of certain $\beta-\mathrm{I} \rightarrow 3$ glucans; but their actual involvement has not been demonstrated. The cytoplasmic glucan of $P$. cinnamomi appears to be a readily accessible reserve carbohydrate. It accumulates in mycelium grown in glucose-rich medium and is consumed upon omission of glucose from the growth medium. A substantial proportion of this soluble cytoplasmic glucan was eventually utilized for the synthesis of 
insoluble cell wall glucan. Whereas glycogen is the conspicuous reserve polysaccharide of some fungi such as Neurospora crassa, Saccharomyces cerevisiae, etc. (see Gorin \& Spencer, 1968), glycogen seems to be absent from the oomycete Phytophthora cinna$m o m i$, the reserve polysaccharide being instead the $\beta-1 \rightarrow 3-\beta-\mathrm{I} \rightarrow 6$ glucan described here. So little is known about the nature and distribution of reserve polysaccharides among fungi that any generalization, with intrinsic phylogenetic value, appears premature (see Klein \& Cronquist, 1967). Suffice it to suggest, for the time being, that the nature of the polysaccharide storage materials in $P$. cinnamomi might be one further example of the biochemical traits which make Oomycetes unique among fungi (see Bartnicki-Garcia, 1969).

We acknowledge the technical assistance of Miss Eleanor Lippman in the experiments on glucose deprivation. This investigation was supported in part by a research grant (AI-06205) from the National Institutes of Health, Bethesda, Md., U.S.A.

\section{REFERENCES}

BARTNICKI-GARCIA, S. (1966). Chemistry of hyphal walls of Phytophthora. Journal of General Microbiology 42, 57 .

BARTNICKI-GARCIA, S. (1968). Cell wall chemistry, morphogenesis and taxonomy of fungi. Annual Review of Microbiology 22, 87.

Bartnicki-Garcia, S. (1969). Cell wall differentiation in the Phycomycetes. Phytopathology 59, 1065.

BARTNICKI-GARCIA, S. \& LipPMAN, E. (1967). Enzymic digestion and glucan structure of hyphal walls of Phytophthora cinnamomi. Biochimica et Biophysica Acta 136, 533.

Bouveng, H. O., Kiessling, H., Lindberg, B. \& McKay, J. (1963). Polysaccharides elaborated by Pullularia pullulans. III. Polysaccharides synthesized from xylose solutions. Acta Chemica Scandinavica 17,1351 .

Buck, K. W., Chen, A. W., Dickerson, A. G. \& Chain, E. B. (1968). Formation and structure of extracellular glucans produced by Claviceps sp. Journal of General Microbiology 5I, 337.

Clarke, A. E. \& Stone, B. A. (1963). Chemistry and biochemistry of $\beta$-1,3-glucans. Review of Pure and Applied Chemistry 13, 134.

EsCHRICH, W. (1956). Kallose. Protoplasma 47, 487.

FRENCH, D. \& WILD, G. M. (1953). Correlation of carbohydrate structure with papergram mobility. Journal of the American Chemical Society 75, $26 \mathrm{I} 2$.

GoRIN, P. A. J. \& SPENCER, J. F. T. (1968). Structural chemistry of fungal polysaccharides. Advances in Carbohydrate Chemistry 23, 367.

HAKOMORI, S. (1964). A rapid permethylation of glycolipid, and polysaccharide catalyzed by methylsulfinyl carbanion in dimethyl sulfoxide. Journal of Biochemistry, Tokyo 55, 205.

Kitahara, M. \& TAKeuchi, Y. (1959). Chemical composition of sclerotia of Sclerotinia libertiana. X. Polyglucosan. Gifu Daigaku Nogakubu Kenkyu Hokoku II, 27.

KLEIN, R. M. \& CRONQUIST, A. (1967). A consideration of the evolutionary and taxonomic significance of some biochemical, micromorphological and physiological characters in the Thallophytes. Quarterly Review of Biology 42, 105.

MANGin, L. (I 894). Sur la constitution de la membrane chez quelques champignons, en particulière chez les polyporée. Bulletin Société Botanique de France 4I, 375.

SANFord, P. A. \& ConRad, H. E. (I966). The structure of the Aerobacter aerogenes A3 (SI) polysaccharide. I. A re-examination using improved procedures for methylation analysis. Biochemistry 5, 1508.

Wallen, L. L., Rhodes, R. A. \& ShulKe, H. R. (1965). Physical properties and chemical composition of $\beta$-glucans from fleshy fungi. Applied Microbiology 13, 272.

Zevenhuizen, L. P. T. M. (1966). Function, structure and metabolism of the intracellular polysaccharide of Arthrobacter. Med. Landbouwhogeschool, Wageningen, Netherlands: Thesis p. 38.

Zevenhuizen, L. P. T. M. \& Bartnicki-Garcia, S. (1969). Chemical structure of the insoluble hyphal wall glucan of Phytophthora cinnamomi. Biochemistry 8, 1496. 